\title{
Catechol[4]arene: The Missing Chiral Member of the Calix[4]arene Family
}

\author{
Suren J. Nemat, Hanna Jędrzejewska, Alessandro Prescimone, Agnieszka Szumna, Konrad Tiefen- \\ bacher
}

\section{Supporting Information Placeholder}

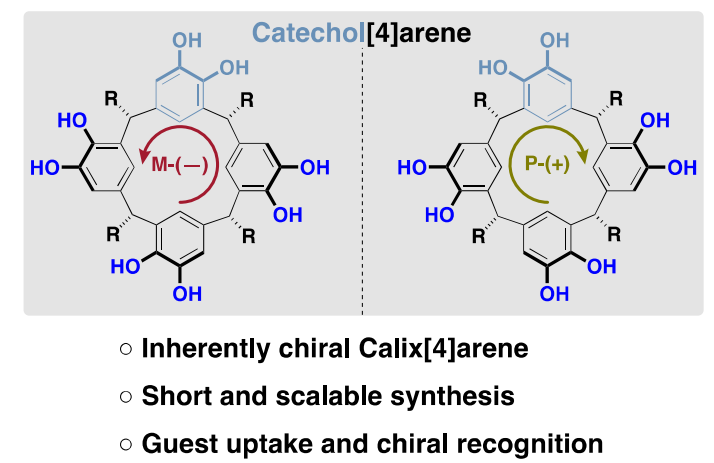

\footnotetext{
ABSTRACT: A missing, inherently chiral member of the calix[4]arene family denoted "catechol[4]arene" was synthesized. Its properties were studied and compared to the ones of its close relatives resorcin[4]arene and pyrogallol[4]arene. This novel supramolecular host exhibits binding capabilities that are superior to its sister molecules in polar media. The enantiomerically pure forms of the macrocycle display modest recognition of chiral ammonium salts.
}

In the broad field of supramolecular chemistry, macrocycles have always played a key role. ${ }^{1}$ Among the synthetic macrocycles, the calix[4] arene family (Figure 1a) stands out as one of the most functional and versatile ones. ${ }^{2}$ Calix[4]arene along with its sister molecules resorcin[4]arene (RS) and pyrogallol[4] arene (PG) are rigid and easily derivatizable ${ }^{3}$ macrocyclic structures that enabled a variety of applications across the fields of material sciences, molecular sensing and drug delivery. ${ }^{4}$ The latter two systems are of particular interest as they are known to self-assemble in apolar media; resulting in the formation of hexameric capsules held together by hydrogen bond networks. ${ }^{5}$ The emerging enclosed space supplemented with its capability to take up neutral and cationic guests resembles enzymatic pockets to some extent. ${ }^{6}$ In the case of RS, these properties have been successfully applied to the catalysis of a growing number of reaction classes.

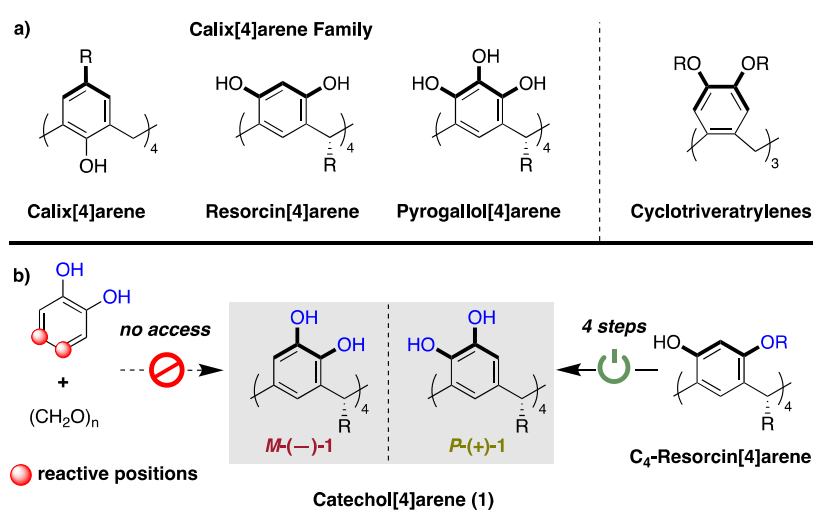

Figure 1. a) Structures of important phenol-based macrocycles. b) Inaccessible one-pot route towards Catechol[4]arene and proposed stepwise approach from $\mathrm{C}_{4}$-Rersorcin[4]arene.

While there are examples of successful asymmetric catalysis employing achiral RS, these reactions exclusively rely on the presence of an optically active co-catalyst to carry the chiral information. ${ }^{8}$ One way of overcoming this limitation would be the use of inherently chiral building blocks. The calix[4]arene fam- 
ily of macrocycles is achiral. Interestingly, a missing chiral relative $( \pm)-1$ (Figure 1b) can be envisioned, we propose the name catechol[4]arene, which to the best of our knowledge has not been reported so far. This inherently chiral constitutional isomer of RS could potentially open access to a range of applications known from other inherently chiral macrocycles, such as asymmetric catalysis, chiral molecular recognition and chiral self-assembly. ${ }^{9}$

The known calix[4]arene family can be easily obtained through electrophilic aromatic substitution of the respective phenols with aldehydes. ${ }^{10}$ However, the directing effects in catechol prevent the direct formation of $\mathbf{1}$. Catechol derivatives reacting with formaldehyde under acidic conditions yield mainly the tricyclic cyclotriveratrylenes (Figure 1a), and no formation of catechol[4]arene has been reported. ${ }^{11}$ We here report the synthesis, characterization and application of the new, inherently chiral, macrocyclic host (1) in its racemic and optically pure form.

It was decided to synthesize this elusive member through derivatization of the literature known compound $( \pm)-4$ (Scheme 1). ${ }^{12}$ The route towards tetramethoxy resorcin[4] arene $( \pm)-4$ starts from the readily available racemic $( \pm)-2$, which can be prepared on the decagram scale in good yields from $O$-methylresorcinol and lauric aldehyde in presence of the Lewis acid $\mathrm{BF}_{3} \cdot \mathrm{Et}_{2} \mathrm{O}$ within a day. ${ }^{13}$

Scheme 1. Synthesis ${ }^{a}$ of Catechol[4] arene 1. $\mathrm{R}=\mathrm{C}_{11} \mathrm{H}_{23}$. a) $\mathrm{Ra}$ cemic synthesis and X-ray crystal structure of $( \pm)-1$. b) Separation of enantiomers of 5 and synthesis of $\boldsymbol{M}-(-)-\mathbf{1} / \boldsymbol{P}-(+)-\mathbf{1}$.

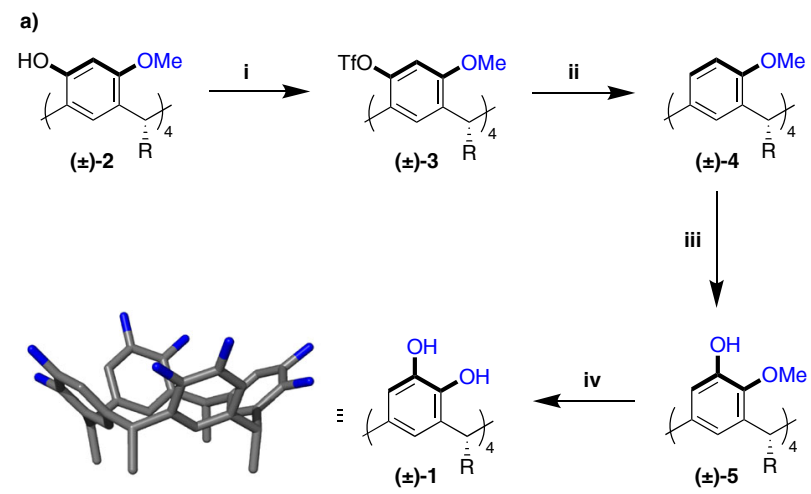

b)

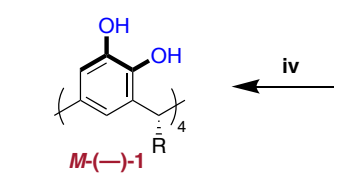

$( \pm)-5$
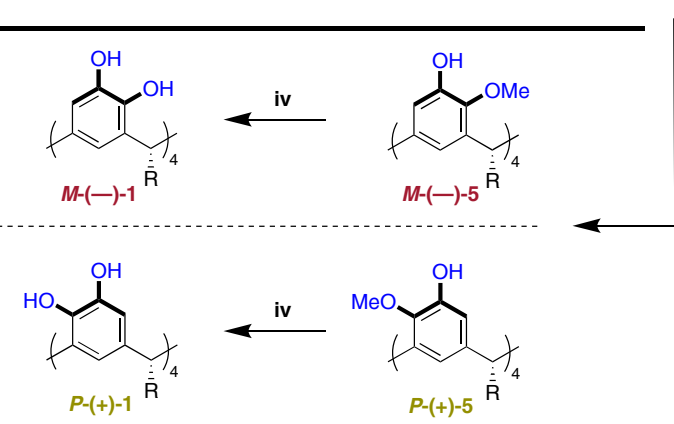

${ }^{a}$ Reagents and conditions: i) $\mathrm{Tf}_{2} \mathrm{O}$, pyridine, DCM, $0{ }^{\circ} \mathrm{C}$ to $\mathrm{rt}, 16 \mathrm{~h}$, 94\%; ii) $\mathrm{NEt}_{3}$, formic acid, $\mathrm{Pd}_{2}[\mathrm{dba}]_{3}(10 \mathrm{~mol} \%$ ), $r a c$-BINAP (20 mol \%), toluene, $120{ }^{\circ} \mathrm{C}, 40 \mathrm{~h}, 86 \%$; iii) $n \mathrm{BuLi}$, TMEDA, Et ${ }_{2} \mathrm{O}$, $-78^{\circ}$ to $\mathrm{rt}, 16 \mathrm{~h}$, then $\mathrm{B}(\mathrm{OMe})_{3},-78^{\circ}$ to $\mathrm{rt}, 8 \mathrm{~h}$, then $\mathrm{NaOH} / \mathrm{H}_{2} \mathrm{O}_{2}$, $-78^{\circ}$ to $\mathrm{rt}, 16 \mathrm{~h}, 47 \%$; iv) $\mathrm{BBr}_{3}, \mathrm{DCM},-78^{\circ}$ to $\mathrm{rt}, 16 \mathrm{~h}, 91 \%$ (M(-)-1: 96\%; P-(+)-1: 97\%).
$( \pm)-2$ is converted to the tetratriflate $( \pm)-3$ in $94 \%$, using literature conditions. ${ }^{12}$ After optimization of the reported conditions, ${ }^{12}$ it was possible to remove the triflates in high yield using $\mathrm{Pd}_{2}[\mathrm{dba}]_{3}, r a c-B I N A P$ and formic acid, to give $( \pm)-4(86 \%)$. The crucial step of the synthesis of $( \pm)-1$ involved the tertafunctionalization of $( \pm)-4$, which was achieved through ortho-lithiation. Ortho-lithiations of Resorcin[4]arene derivatives are known, ${ }^{14}$ but typically require two $O$-alkylated directing groups per lithiation site. In order to achieve reasonable yields with the single methoxy directing group per aromatic moiety in ( \pm -4, a large excess of $n \mathrm{BuLi}$ and TMEDA, as well as long reaction times and a precise temperature program were required. As a result of these optimizations, the yield for the terahydroxylated product $( \pm)-5$, obtained by subsequent borylation and oxidation to the phenol, ${ }^{15}$ was increased to $47 \%$ while at the same time ensuring scalability of the reaction. At this stage it was possible to readily separate the enantiomers by preparative, chiral HPLC to give optically pure $\boldsymbol{M}-(-)-1$ and $\boldsymbol{P}-(+)-1$ (Scheme 1b, see Figure S9). In the final step, the methyl protecting groups were removed using boron tribromide, followed by a final purification by column chromatography to yield either $( \pm)-\mathbf{1}$ or enantiopure $\boldsymbol{M}$-( $-\mathbf{- 1}$ and $\boldsymbol{P}-(+)-\mathbf{1}$ in yields $>90 \%$. Catechol[4] arene was extensively characterized by ESI-HRMS, NMR- and IRspectroscopy, as well as X-ray crystallography (Scheme 1a) to confirm the macrocyclic structure.

Single crystals suitable for X-ray crystallography were obtained from a solution of $( \pm)-\mathbf{1}$ in DMSO at room temperature. The crystal structure analysis of catechol[4] arene (space group: $P-1)$ revealed a pseudo-boat conformation $\left(C_{2 \mathrm{v}}\right.$-symmetry, Table 1). While this deviation from ideal $C_{4}$-symmetric crown conformation is observed for its sister molecules RS and PG in the solid state, it is amplified in the case of $1 .{ }^{16}$ This is reflected in the distances between the phenolic units of the macrocycle, for which 1 exhibits both the shortest $(\mathrm{a}=7.73 \AA)$ and longest ( $b=9.31 \AA$ ) distance between two opposing aromatic faces across all three systems (Table 1, see Figures S6-S8 and Supporting Information Appendix B for details). Further structural differences between 1, RS and PG are observed for the distortion of the tetrahedral angles $\alpha$ at the bridging methane carbons. While for the latter two systems, these four angles vary by less than $1.5^{\circ}, 1$ shows considerable variability of $\Delta \alpha_{\max }=4.7^{\circ}$. These findings suggest a decreased rigidity of the framework that enables a more flexible conformation in comparison to its sister macrocycles.

Table 1. X-ray crystal structure of $( \pm)-1$ with the distances $a$ and $b$ and the tetrahedral angle $\alpha$. Values for $a, b$ and the maximum variability of the tetrahedral angle $\Delta \alpha_{\max }$ for 1 , RS and PG. ${ }^{16}$

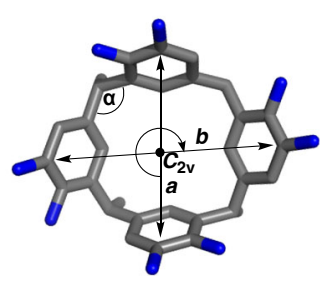

\begin{tabular}{|c|c|c|c|}
\hline Property & 1 & RS & PG \\
\hline$a / \AA ̊$ & 7.73 & 7.81 & 7.75 \\
\hline$b / A ̊$ & 9.31 & 9.25 & 8.95 \\
\hline$\Delta \boldsymbol{\alpha}_{\max }{ }^{\circ}$ & 4.7 & 1.4 & 0.7 \\
\hline
\end{tabular}

In order to investigate the chiral properties of $\mathbf{1}$ in solution, its enantiomers were analyzed by CD-spectroscopy and optical rotation measurements. These characterization methods along with DFT calculations ${ }^{17}$ allowed to assign the axial chirality and 
optical activity for $\boldsymbol{M}-(-)-\mathbf{1}$ and $\boldsymbol{P}-(+)-\mathbf{1}$ (Figure 2, see Supporting Information Chapter 2.5). ${ }^{18}$
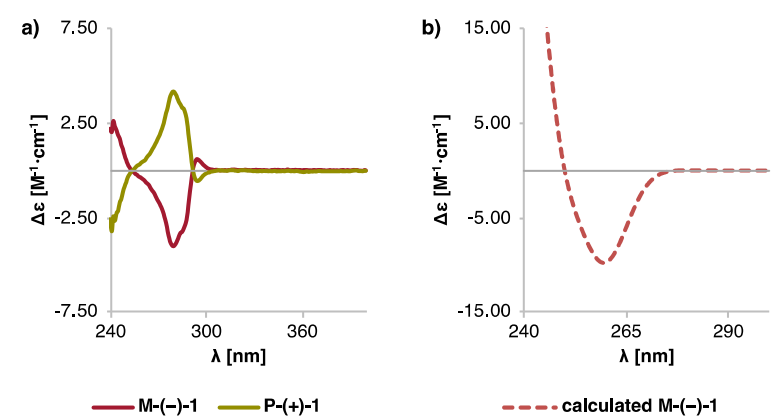

Figure 2. a) Experimental CD spectra of enantiomers $\boldsymbol{M}-(-)-\mathbf{1}$ and $\boldsymbol{P}-(+)-\mathbf{1}$ in chloroform; b) Calculated CD spectrum for $\boldsymbol{M}-(-)-\mathbf{1}$ (TD DFT B3LYP/6-31G(d,p)) in chloroform.

After having confirmed the structure, its ability to self-assemble was explored. $( \pm)-1$ turned out to be poorly soluble in chloroform and no evidence for the formation of larger self-assembled structures was obtained by NMR spectroscopy (see Supporting Information Chapter 2.2). Also forcing conditions like prolonged heating, ultrasonication, templating and ball-milling failed to induce any form of soluble higher structure. ${ }^{19}$ The same was true for the optically active forms, $\boldsymbol{M}-(-)-\mathbf{1}$ or $\boldsymbol{P}-(+)-$ 1. We suspect that the absence of hydrogen bonds between the aromatic units of the macrocycle, which stabilize the crown conformation in case of $\mathbf{R S}$ and $\mathbf{P G}$, is detrimental to its aptitude for self-assembly. In polar solvents such as acetone, diethyl ether or methanol, 1 exhibited good solubility. The latter solvent is particularly interesting, as RS and PG are practically insoluble in alcoholic solvents. The solvation of $\mathbf{1}$ is presumably facilitated through the increased flexibility of the macrocyclic framework.

The DFT calculations of $\mathbf{1}$ suggest a conformation with $C_{2 \mathrm{v}}$ symmetry as major species in solution (see Figure S12, Table S3 and Supporting Information Appendix C). Nevertheless, the ${ }^{1} \mathrm{H}-\mathrm{NMR}$ spectra suggest a well-defined $\mathrm{C}_{4}$-symmetric macrocycle, independent of the solvent and devoid of any signal splitting typically expected for $C_{2 v}$-symmetry. Consequently, it can be proposed that two rapidly interconverting pseudo-boat conformers are present in solution. Similar observations have been made for a related system. ${ }^{20}$

In light of the systematic differences between $\mathbf{1}$ and its sister macrocycles, the question arose to which extent their guest binding capability differs. We investigated the binding of organic ammonium guests. Acetone was chosen as solvent due to the good solubility of all three hosts (see Figure S2). Initial experiments with $( \pm)-1$ and varying concentrations of methylpyridinium guests G1 and G2 showed considerable shifts of the host and guest signals indicating the formation of host-guest complexes in fast-exchange on the NMR timescale (Figure 3, see Supporting Information Chapter 3.1).

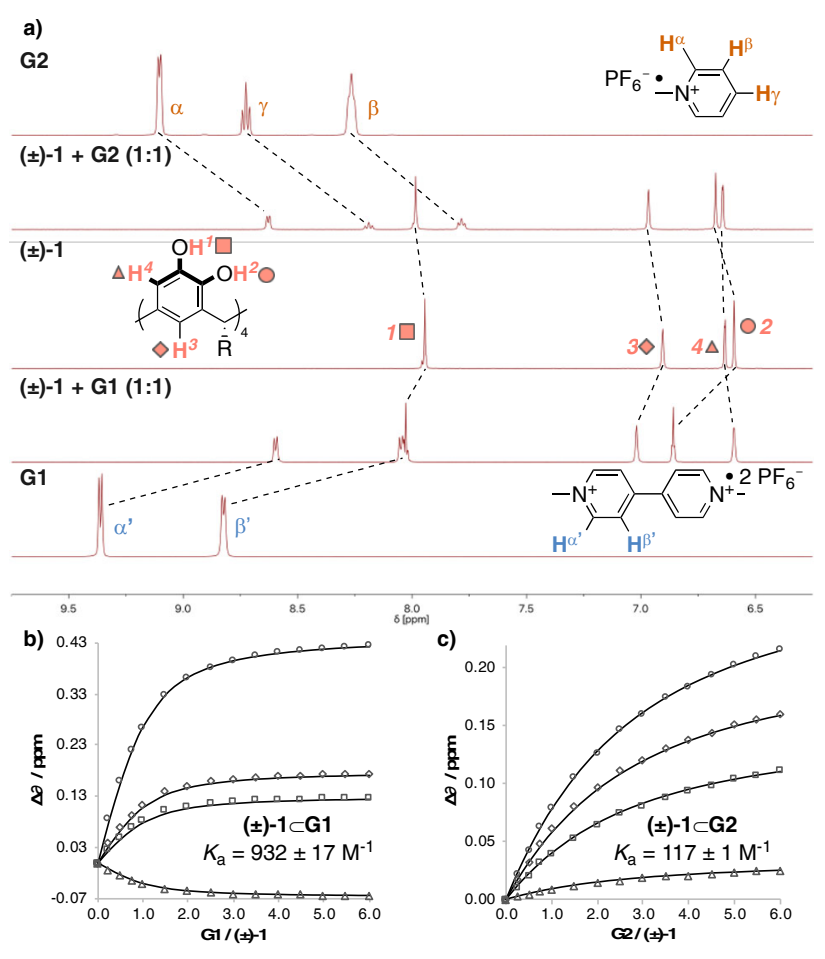

Figure 3. Host guest interactions of ( \pm -1 1 with guests G1 and G5. a) Partial ${ }^{1} \mathrm{H}-\mathrm{NMR}$ spectra of G2; ( \pm )-1 + G2 $(1: 1,4 \mathrm{mM})$; ( \pm )-1; ( \pm$)-\mathbf{1}+\mathbf{G 1}(1: 1,4 \mathrm{mM}) ; \mathbf{G 1}$; b),c) NMR shifts $\Delta \delta$ of $( \pm)-\mathbf{1}$ signals with increasing equivalents of $\mathbf{G 1}$ and $\mathbf{G 2}$ and their corresponding binding constants $K_{\mathrm{a}}$ for $( \pm)-\mathbf{1} \subset \mathbf{G 1}$ and $( \pm)-\mathbf{1} \subset \mathbf{G} \mathbf{2}$. All spectra were recorded in acetone- $d_{6}$.

Interestingly, binding of $\mathbf{G 1}$ and $\mathbf{G 2}$ was substantially higher than in RS and PG. A small library of five achiral guest molecules was investigated, comprising mono- and dicationic (G1, G2) methylpyridinium salts, as well as benzylic (G3) and phenylic (G4, G5) tri- and dimethylammonium salts. The hexafluorophosphate counterion ensured good solubility of these salts in acetone. As all three macrocycles were in fast exchange with their respective guests, the binding constants $K_{\mathrm{a}}$ for the host-guest complexes were determined by means of ${ }^{1} \mathrm{H}-\mathrm{NMR}$ titration in acetone- $d_{6}$ (Table 2$){ }^{21}$

Table 2. Binding constants $K_{\mathrm{a}}$ of $( \pm)-1$, RS and PG and the corresponding guest $\left(\mathrm{M}^{-1}\right)$, determined by ${ }^{1} \mathrm{H}$-NMR titration in acetone- $d_{6}$. Titrations performed at $4 \mathrm{mM}$ of host. n.d.: $K_{\text {a }}$ could not be determined by means of NMR titration.

\begin{tabular}{cccc} 
G\# & $\begin{array}{c}( \pm)-1 \\
K_{\mathrm{a}} / \mathrm{M}^{-1}\end{array}$ & $\begin{array}{c}\text { RS } \\
K_{\mathrm{a}} / \mathrm{M}^{-1}\end{array}$ & $\begin{array}{c}\text { PG } \\
K_{\mathrm{a}} / \mathrm{M}^{-1}\end{array}$ \\
\hline G1 & $932 \pm 17$ & $47.2 \pm 0.80$ & $152 \pm 3.2$ \\
G2 & $117 \pm 0.80$ & $10.5 \pm 0.18$ & $34.1 \pm 0.10$ \\
G3 & $32.7 \pm 0.22$ & n.d. & $15.8 \pm 0.045$ \\
G4 & $83.3 \pm 1.3$ & $12.5 \pm 0.22$ & $39.0 \pm 0.51$ \\
G5 & $36.5 \pm 0.19$ & $6.75 \pm 0.076$ & $34.3 \pm 0.33$ \\
\hline
\end{tabular}

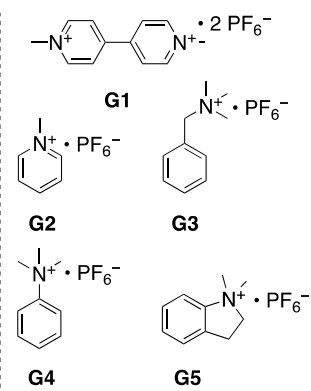


While all host-guest complexes showed only weak to moderate binding affinities, $( \pm)-\mathbf{1}$ outperformed the other systems in every case tested. Surprisingly, RS demonstrated the weakest binding capabilities which stands in stark contrast to its properties as a hexameric capsule in apolar solvents. ${ }^{6 a}, 6 \mathrm{e}$

Upon assessing the achiral binding capabilities we shifted our attention towards chiral recognition using enantiopure $\boldsymbol{M}-(-)-\mathbf{1}$ and $\boldsymbol{P}-(+)-1$. Initial tests were performed with $(\boldsymbol{S})-\mathbf{G 6}$, a methylated derivative of 1-indamine, an important drug intermediate. ${ }^{22}$ The ${ }^{1} \mathrm{H}-\mathrm{NMR}$ in acetone- $d_{6}$ of a 1:2 mixture of $( \pm)-1$ and (S)-G6 demonstrated two distinguished sets of signals for the each of the diastereomeric complexes $\boldsymbol{M}-(-)-\mathbf{1} \subset(S)-G 6$ and $\boldsymbol{P}$ $(+)-1 \subset(S)-G 6$ (Figure $4 b)$. An exact assignment of the peaks was accomplished by comparison with spectra of pure $\boldsymbol{P}-(+)-\mathbf{1}$ and (S)-G6 (Figure 4c).

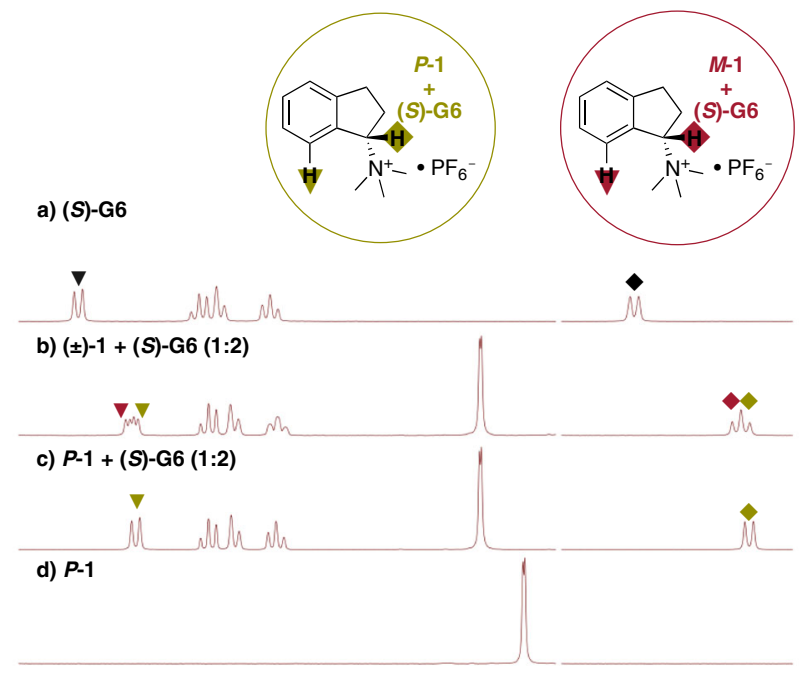

Figure 4. ${ }^{1} \mathrm{H}-\mathrm{NMR}$ spectra of a) (S)-G6; b) $4 \mathrm{mM}( \pm)-1$ and $8 \mathrm{mM}$ (S)-G6; c) 4 mM $\boldsymbol{P}$-(+)-1 and $8 \mathrm{mM}$ (S)-G6; d) 4 mM $\boldsymbol{P}$-(+)-1. All spectra were recorded in acetone- $d_{6}$.

In order to identify any form of enantioselective binding, a library of four chiral ammonium salts was compiled and the binding constants $K_{\mathrm{a}}$ for each host-guest pair were determined via ${ }^{1} \mathrm{H}-\mathrm{NMR}$ titration in acetone- $d_{6}$ (Table 3 , see Supporting Information Chapter 3.2).

Table 3. Binding constants $K_{\mathrm{a}}$ of $M-(-)-1$ and $P-(+)-1$ and the corresponding chiral guest $\left(M^{-1}\right)$, determined by ${ }^{1} \mathrm{H}-\mathrm{NMR}$ titration in acetone- $d_{6}$. Titrations performed at $4 \mathrm{mM}$ of host.

\begin{tabular}{cccc} 
G\# & $\begin{array}{c}M-(-)-1 \\
K_{a} / M^{-1}\end{array}$ & $\begin{array}{c}P_{-}(+)-1 \\
K_{a} / M^{-1}\end{array}$ & $\begin{array}{c}K_{a(M)} \\
K_{a(P)}\end{array}$ \\
\hline (S)-G6 & $58.4 \pm 0.11$ & $47.3 \pm 0.085$ & $1.23: 1$ \\
$(R)-G 7$ & $63.8 \pm 0.14$ & $79.4 \pm 0.23$ & $1: 1.24$ \\
$(R)-G 8$ & $37.7 \pm 0.16$ & $55.8 \pm 0.26$ & $1: 1.48$ \\
$(S)-G 9$ & $273 \pm 0.95$ & $268 \pm 0.66$ & $1.02: 1$ \\
\hline
\end{tabular}

For the structurally related guests $(S)$-G6, $(R)-G 7$ and $(R)$ G8 a trend for selectivity of $\boldsymbol{M}-(-)-1$ towards $S$ and $P-(+)-1$ towards $R$ configured guests was observed. In the case of the structurally closely related guests $(S)$-G6 and $(R)-\mathbf{G 7}$, a chiral binding preference is detectable with $K_{\mathrm{a}}(\boldsymbol{M}) / K_{\mathrm{a}}(\boldsymbol{P})$ values amounting to $1.23: 1$ and $1: 1.24$, respectively. The overall binding affinity increased with the dicationic guest $(\boldsymbol{S})$-G9 in accordance to our previous findings with G1. At the same time, binding selectivity with $(\boldsymbol{S})$-G9 became almost negligible. This observation may be explained by examining the binding motifs of this particular guest. While $(\boldsymbol{S})$-G9 possesses two cationic sites, our results from titration of the achiral guests $\mathbf{G 2}$ and $\mathbf{G 5}$ with racemic $( \pm)$-1 suggest $(S)$-G9 to primarily bind via its methylpyridinium moiety. Since the chiral information, located on the pyrrolidinium moiety, points away from the chiral cavity of $\mathbf{1}$, the selectivity might be lost. The strongest chiral recognition was observed for $(\boldsymbol{R})$-G8. In this case, the chiral center at the benzylic position displays a high degree of rotational freedom, which may be translated into an enhanced adaptability towards the chiral environment of the host, thus expressing the highest selectivity.

In summary, we have developed a short, high yielding $(39 \%$ overall yield), and scalable synthesis of a missing member of the calix[4]arene family denoted "catechol[4]arene". This new, inherently chiral macrocycle was characterized in detail and compared to its sister molecules resorcin[4] arene and pyrogallol[4]arene. $\mathbf{1}$ is well soluble in alcohols, while showing poor solubility in apolar solvents such as chloroform, which sets it apart from its close relatives RS and PG. In contrast to $\mathbf{R S}$ and PG, no evidence for the formation of larger self-assembled structures was found. However, $( \pm)-1$ exhibited guest binding capabilities in polar solvents which exceeded those of $\mathbf{R S}$ and PG. This property may be attributed to its more flexible conformation that adapts to maximize the interaction with the individual guests. The enantiomers $\boldsymbol{M}-(-)-\mathbf{1}$ and $\boldsymbol{P}-(+)-\mathbf{1}$ were accessed by preparative, chiral HPLC and their absolute configuration was assigned by $\mathrm{CD}$-spectroscopy and quantum mechanical calculations. The optically active macrocycles showed modest chiral recognition of optically active ammonium salts. We believe that $\mathbf{1}$ could serve as a readily available, inherently chiral macrocyclic platform for further derivatization and applications in chiral recognition, asymmetric catalysis and chiral self-assembly.

\section{ASSOCIATED CONTENT}

Supporting Information

The Supporting Information is available free of charge on the ACS Publications website.

Experimental details and NMR spectra of new compounds (PDF) Crystallographic data for ( \pm )-1 (CIF)

\section{AUTHOR INFORMATION}

Corresponding Author

Konrad Tiefenbacher - Department of Chemistry, University of Basel, 4058 Basel, Switzerland; Department of Biosystems Science and Engineering, ETH Zurich, 4058 Basel, Switzerland; orcid.org/0000-0002-3351-6121; Email: konrad.tiefenbacher@unibas.ch,tkonrad@ethz.ch

Authors 
Suren J. Nemat - Department of Chemistry, University of Basel, 4058 Basel, Switzerland; orcid.org/0000-0002-1894-4021

Hanna Jędrzejewska - Institute of Organic Chemistry Polish Academy of Sciences, Kasprzaka 44/52, 01-224 Warsaw, Poland. Alessandro Prescimone - Department of Chemistry, University of Basel, 4058 Basel, Switzerland

Agnieszka Szumna - Institute of Organic Chemistry Polish Academy of Sciences, Kasprzaka 44/52, 01-224 Warsaw, Poland.

\section{Present Addresses}

$\dagger$ If an author's address is different than the one given in the affiliation line, this information may be included here.

\section{Author Contributions}

K.T. supervised the project. S.J.N. and K.T. conceived and planned the project. S.J.N. carried out all experimental work. H.J. and A.S. performed and interpreted the DFT calculations. A.P. performed the X-ray crystallography. The first draft of the manuscript was compiled by S.J.N. and K.T.. All authors contributed to the final version.

\section{Notes}

The authors declare no competing financial interest.

\section{ACKNOWLEDGMENT}

This work was supported by funding from the Swiss National Science Foundation (Grant SNF: 200021_178714), by the NCCR Molecular Systems Engineering and by the Wroclaw Centre for Networking and Supercomputing (grant No. 299). The authors thank Dr. Michael Pfeffer for HR-MS analysis, as well as Severin F. Merget and Fabian Bissegger for their contributions to the NMR experiments.

\section{REFERENCES}

(1) (a) Diederich, F.; Stang, P. J.; Tykwinski, R. R., Modern Supramolecular Chemistry: Strategies for Macrocycle Synthesis. Wiley-VCH: Weinheim, 2008. (b) Steed, J. W.; Atwood, J. L., Supramolecular Chemistry. John Wiley \& Sons Ltd.: Chichester, 2009. (c) Steed, J. W.; Gale, P. A., Supramolecular Chemistry: From Molecules to Nanomaterials. John Wiley \& Sons Ltd.: Chichester, 2012. (d) Atwood, J. L.; Gokel, G. W.; Barbour, L. J., Comprehensive Supramolecular Chemistry II. Elsevier: Oxford, 2017.

(2) (a) Gutsche, C. D., Calixarenes Revisited. The Royal Society of Chemistry: Cambridge, 1998. (b) Gutsche, C. D., Calixarenes: An Introduction. The Royal Society of Chemistry: Cambridge, 2008.

(3) (a) Timmerman, P.; Verboom, W.; Reinhoudt, D. N. Tetrahedron 1996, 52, 2663. (b) Asfari, Z.; Böhmer, V.; Harrowfield, J.; Vicens, J.; Saadioui, M., Calixarenes 2001. Kluwer Academic Publishers: Dordrecht, 2001. (c) Lavendomme, R.; Zahim, S.; De Leener, G.; Inthasot, A.; Mattiuzzi, A.; Luhmer, M.; Reinaud, O.; Jabin, I. Asian J. Org. Chem. 2015, 4, 710. (d) Kobayashi, K.; Yamanaka, M. Chem. Soc. Rev. 2015, 44, 449. (e) Scott, M. P.; Sherburn, M. S., Resorcinarenes and Pyrogallolarenes. In Comprehensive Supramolecular Chemistry II; Elsevier: Oxford, 2017; pp 337-374.

(4) (a) Nimse, S. B.; Kim, T. Chem. Soc. Rev. 2013, 42, 366. (b) Kumar, R.; Sharma, A.; Singh, H.; Suating, P.; Kim, H. S.; Sunwoo, K.; Shim, I.; Gibb, B. C.; Kim, J. S. Chem. Rev. 2019, $119,9657$.
(5) (a) MacGillivray, L. R.; Atwood, J. L. Nature 1997, 389, 469. (b) Gerkensmeier, T.; Iwanek, W.; Agena, C.; Fröhlich, R.; Kotila, S.; Näther, C.; Mattay, J. Eur. J. Org. Chem. 1999, 1999 , 2257.

(6) (a) Shivanyuk, A.; Rebek, J. Proc. Natl. Acad. Sci. U.S.A 2001, 98, 7662. (b) Avram, L.; Cohen, Y.J. Am. Chem. Soc. 2002, 124, 15148. (c) Avram, L.; Cohen, Y. J. Am. Chem. Soc. 2003, 125, 16180. (d) Avram, L.; Cohen, Y.; Rebek Jr, J. Chem. Commun. 2011, 47, 5368. (e) Zhang, Q.; Catti, L.; Kaila, V. R. I.; Tiefenbacher, K. Chem. Sci. 2017, 8, 1653.

(7) (a) Cohen, Y.; Slovak, S.; Avram, L., Hydrogen Bond Hexameric Capsules: Structures, Host-Guest Interactions, Guest Affinities, and Catalysis. In Calixarenes and Beyond; Springer International Publishing: Cham, 2016; pp 811-842. (b) Zhang, Q.; Catti, L.; Tiefenbacher, K. Acc. Chem. Res. 2018, 51, 2107. (c) Gaeta, C.; Talotta, C.; De Rosa, M.; La Manna, P.; Soriente, A.; Neri, P. Chem. Eur. J. 2019, 25, 4899. (d) Zhu, Y.; Rebek Jr, J.; Yu, Y. Chem. Commun. 2019, 55, 3573.

(8) (a) Bräuer, T. M.; Zhang, Q.; Tiefenbacher, K. Angew. Chem. Int. Ed. 2016, 55, 7698. (b) Bräuer, T. M.; Zhang, Q.;

Tiefenbacher, K. J. Am. Chem. Soc. 2017, 139, 17500. (c) La Manna, P.; De Rosa, M.; Talotta, C.; Gaeta, C.; Soriente, A.; Floresta, G.; Rescifina, A.; Neri, P. Org. Chem. Front. 2018, 5, 827.

(9) (a) Szumna, A. Chem. Soc. Rev. 2010, 39, 4274. (b) Homden, D. M.; Redshaw, C. Chem. Rev. 2008, 108, 5086. (c) Mutihac, L.; Lee, J. H.; Kim, J. S.; Vicens, J. Chem. Soc. Rev. 2011, 40, 2777. (d) Wierzbicki, M.; Jędrzejewska, H.; Szumna, A., Chiral Calixarenes and Resorcinarenes. In Calixarenes and Beyond; Springer International Publishing: Cham, 2016; pp 13-41. (10) (a) Baeyer, A. Ber. Dtsch. Chem. Ges. 1872, 5, 280. (b) Niederl, J. B.; Vogel, H. J. J. Am. Chem. Soc. 1940, 62, 2512. (c) Zinke, A.; Kretz, R.; Leggewie, E.; Hössinger, K.; Hoffmann, G.; Weber v. Ostwalden, P.; Wiesenberger, E.; Sobotka, M.; Kretz, R. Monatsh. Chem. 1952, 83, 1213 .

(11) Collet, A. Tetrahedron 1987, 43, 5725.

(12) (a) Page, P. C. B.; Bygrave, T. R.; Chan, Y.; Heaney, H.; McKee, V. Eur. J. Org. Chem. 2011, 2011, 3016. (b) Smith, J. N.; Lucas, N. T. Chem. Commun. 2018, 54, 4716.

(13) (a) McIldowie, M. J.; Mocerino, M.; Skelton, B. W.; White, A. H. Org. Lett. 2000, 2, 3869. (b) Tero, T.-R.; Suhonen, A.; Salorinne, K.; Campos-Barbosa, H.; Nissinen, M. Org. Lett. 2013, 15,1096

(14) (a) Ngodwana, L.; Kleinhans, D. J.; Smuts, A.-J.; van Otterlo, W. A. L.; Arnott, G. E. RSC $A d v$. 2013, 3, 3873. (b) Tan, D. A.; Mocerino, M. J. Incl. Phenom. Macrocycl. Chem. 2018, 91, 71. (c) Loose, D.; Aniol, A.; Feigel, M.; Röhling, S.; Dyker, G. Eur. J. Org. Chem. 2020, 2020, 35.

(15) (a) Irwin, J. L.; Sherburn, M. S. J. Org. Chem. 2000, 65, 602. (b) Irwin, J. L.; Sherburn, M. S. J. Org. Chem. 2000, 65, 5846 (16) (a) Atwood, J. L.; Szumna, A. J. Supramol. Chem. 2002, 2 , 479-482; CSD Refcode AJUSAZ. (b) Kvasnica, M.; Chapin, J. C.; Purse, B. W. Angew. Chem. Int. Ed. 2011, 50, 2244-2248; CSD Refcode AMOSAX. (c) Groom, C. R.; Bruno, I. J.; Lightfoot, M. P.; Ward, S. C. Acta Crystallographica Section B 2016, 72, 171. (17) Frisch, M. J.; Trucks, G. W.; Schlegel, H. B.; Scuseria, G. E.; Robb, M. A.; Cheeseman, J. R.; Scalmani, G.; Barone, V.; Petersson, G. A.; Nakatsuji, H.; Li, X.; Caricato, M.; Marenich, A. V.; Bloino, J.; Janesko, B. G.; Gomperts, R.; Mennucci, B.; Hratchian, H. P.; Ortiz, J. V.; Izmaylov, A. F.; Sonnenberg, J. L.; Williams; Ding, F.; Lipparini, F.; Egidi, F.; Goings, J.; Peng, B.; Petrone, A.; Henderson, T.; Ranasinghe, D.; Zakrzewski, V. G.; Gao, J.; Rega, N.; Zheng, G.; Liang, W.; Hada, M.; Ehara, M.; Toyota, K.; Fukuda, R.; Hasegawa, J.; Ishida, M.; Nakajima, T.; Honda, Y.; Kitao, O.; Nakai, H.; Vreven, T.; Throssell, K.; Montgomery Jr., J. A.; Peralta, J. E.; Ogliaro, F.; Bearpark, M. J.; Heyd, J. J.; Brothers, E. N.; Kudin, K. N.; Staroverov, V. N.; 
Keith, T. A.; Kobayashi, R.; Normand, J.; Raghavachari, K.; Rendell, A. P.; Burant, J. C.; Iyengar, S. S.; Tomasi, J.; Cossi, M.; Millam, J. M.; Klene, M.; Adamo, C.; Cammi, R.; Ochterski, J. W.; Martin, R. L.; Morokuma, K.; Farkas, O.; Foresman, J. B.; Fox, D. J. Gaussian 09, Revision E.01, Gaussian Inc.: Wallingford, CT, 2009.

(18) (a) Kuberski, B.; Pecul, M.; Szumna, A. Eur. J. Org. Chem. 2008, 2008, 3069. (b) Iwanek, W.; Stefańska, K.; Szumna, A.; Wierzbicki, M. RSC Adv. 2016, 6, 13027. (c) Wierzbicki, M.; Głowacka, A. A.; Szymański, M. P.; Szumna, A. Chem. Commun. 2017, 53, 5200 .
(19) (a) Tiefenbacher, K.; Zhang, K.-d.; Ajami, D.; Rebek Jr., J. J. Phys. Org. Chem. 2015, 28, 187. (b) Grajda, M.; Lewińska, M. J.; Szumna, A. Org. Biomol. Chem. 2017, 15, 8513. (c) Journey, Sara N.; Teppang, K. L.; Garcia, C. A.; Brim, S. A.; Onofrei, D.; Addison, J. B.; Holland, G. P.; Purse, B. W. Chem. Sci. 2017, 8, 7737.

(20) Kumar, P.; Venkatakrishnan, P. Org. Lett. 2018, 20, 1295.

(21) Thordarson, P. Chem. Soc. Rev. 2011, 40, 1305.

(22) Youdim, M. B. H.; Gross, A.; Finberg, J. P. M. Br. J. Pharmacol. 2001, 132, 500 . 